\title{
109. Strain modal analysis and fatigue residual life prediction of vibrating screen beam
}

\author{
Zerong Zhang \\ College of Electromechanical Engineering, Qingdao University of Science and Technology, \\ Qingdao, China \\ E-mail: cba1998@126.com
}

Received 17 December 2016; accepted 20 December 2016

DOI https://doi.org/10.21595/jme.2016.18113

\begin{abstract}
The displacement and strain modal analysis of vibrating screen beam is carried out, the results show that the relative deviation of the modal frequencies between intact and damaged beam is small, the displacement mode shapes of the damaged beam have no obvious variation, but the strain mode shapes have mutation peaks at the damaged location for the damaged beam. Therefore, a damage index is defined as the rate of strain modal change between damaged and intact beam. The rate of strain modal change increases with the increasing damage extent of the beam. The initial fatigue crack length is related to the damage extent of the beam; the fatigue crack propagation residual life of the beam is predicted by the Paris law. The results show that the rate of strain modal change is a sensitive and reliable damage index for indicating the damage location and damage extent. The predictions of the damage extent and the crack propagation residual life of the vibrating screen beam are beneficial to dynamic optimization design, which can improve the service life of the vibrating screen.
\end{abstract}

Keywords: vibrating screen, strain modal analysis, multiple damage, crack propagation, residual life.

\section{Introduction}

Large vibrating screen is widely used for screening, grading and dewatering in mining, metallurgy and chemical industries [1-3]. In the working process the beam of the vibrating screen is impacted by the particles and corroded by slime water, which result in fatigue fracture of the beam and suspended production [4]. If the fatigue crack of the beam is diagnosed and the fatigue residual life of the beam is predicted, production accidents and economic losses could be avoided. The strain modal parameters is more sensitive to fatigue cracks than the displacement modal parameters [5], so strain modal analysis is used for damage identification in the vibrating screen beam. Adewuyi and Wu used modal macro-strain flexibility methods for damage localization in flexural structures [6]. He et al. proposed a method that requires low-frequency modes and does not require mass normalization of parameters, thus making the method suitable for nondestructive dynamic damage detection of large structures under ambient excitation [7]. Cha and Buyukozturk used modal strain energy as a damage index in structural health monitoring and proposed hybrid multi-objective optimization algorithms to detect minor damages in various three-dimensional steel structures [8].

In this study, we built sensitive and reliable damage index of the vibrating screen beam based on strain modal analysis, which can predict the damaged extent and location of the beam. Then according to the fatigue crack length, the fatigue crack propagation residual life is predicted by the Paris law.

\section{Damage identification theory based on strain modal analysis}

The vibrating screen is a multiple degrees of freedom system, the free vibration equation is:

$\mathbf{M} \ddot{\mathbf{x}}+\mathbf{C} \dot{\mathbf{x}}+\mathbf{K x}=0$

where $\mathbf{M}, \mathbf{C}$ and $\mathbf{K}$ are the mass, the damping and the stiffness matrices, respectively [9]. 
From Eq. (1) we can get:

$\left(\mathbf{K}-\omega_{i}^{2} \mathbf{M}\right) \boldsymbol{\Phi}_{i}=0$,

where $\omega_{i}$ is the $i$ th modal frequency, $\boldsymbol{\Phi}_{i}$ is the $i$ th mode shape.

According to finite element theory, the relationship between strain mode shape $\Psi^{\varepsilon}$ and displacement mode shape $\boldsymbol{\Phi}$ is:

$\boldsymbol{\Psi}_{i}^{\varepsilon}=\mathbf{B} \boldsymbol{\Phi}_{i}$,

$\mathbf{B}=D \mathbf{P A}^{-1} \boldsymbol{\beta}$,

where $D$ is the linear differential operator, $\mathbf{P}$ is displacement function matrix, $\mathbf{A}$ is numerical matrix, $\boldsymbol{\beta}$ is coordinate transformation matrix [10].

Substituted Eq. (3) into Eq. (2), we can get:

$\left(\mathbf{K}-\omega_{i}^{2} \mathbf{M}\right) \mathbf{B}^{-1} \Psi_{i}^{\varepsilon}=0$.

Compared Eq. (2) and Eq. (5), the displacement mode is corresponding to the strain mode and both have the same modal frequency, modal mass and modal stiffness.

When the vibrating screen structure generates fatigue crack, its stiffness, frequency and mode shape is different from the intact structure, which is:

$\left((\mathbf{K}+\Delta \mathbf{K})-\left(\omega_{i}+\Delta \omega_{i}\right)^{2} \mathbf{M}\right)\left(\boldsymbol{\Phi}_{i}+\Delta \boldsymbol{\Phi}_{i}\right)=0$.

Accordingly, the strain modal parameters is varied:

$\left((\mathbf{K}+\Delta \mathbf{K})-\left(\omega_{i}+\Delta \omega_{i}\right)^{2} \mathbf{M}\right) \mathbf{B}^{-1}\left(\Psi_{i}^{\varepsilon}+\Delta \Psi_{i}^{\varepsilon}\right)=0$.

The damage location and damage extent can be predicted by the variation of the modal stiffness, modal frequency or the mode shape theoretically. In fact, the fatigue crack damage mainly lead to the local stiffness varied, so the variation of the modal frequencies and displacement mode shapes are small, while the variation of the strain mode shape is large $[11,12]$.

In order to improve the effectiveness and reliability of the fatigue damage diagnosis result, we recommend the strain modal change ratio $(S R)$ as the damage index:

$S R=\frac{1}{m} \sum_{i=1}^{m} \frac{\Delta \Psi_{i}^{\varepsilon}}{\Psi_{i}^{\varepsilon}}$

where $m$ is the effective mode orders.

\section{Displacement and strain modal analysis of the vibrating screen beam}

In this paper, we select the $27 \mathrm{~m}^{2}$ large linear vibrating screen as the research object, its finite element model is shown in Fig. 1. The beam of the vibrating screen is tubular beam structure, its inner diameter is $300 \mathrm{~mm}$, outside diameter is $320 \mathrm{~mm}$, thickness is $10 \mathrm{~mm}$ and beam length is $3600 \mathrm{~mm}$. The material of the beam is 20 carbon steel, its elastic modulus is $213 \mathrm{GPa}$, density is $7.8 \times 10^{3} \mathrm{~kg} / \mathrm{m}^{3}$, Poisson's ratio is 0.28 . Because the beam is thin-walled tube structure, the shell element of SHELL181 with six degrees of freedom and 4 nodes is more suitable than beam element for finite element modal analysis [13].

The locations of the fatigue crack for the beam often generate at the midpoint and quarter of the beam, so the locations of the simulated fatigue crack are assumed at the midpoint and quarter of the No. 4 beam in FEM model. The fatigue crack is assumed a transverse perforation crack with 
width of $1 \mathrm{~mm}$, as shown in Fig. $2[14,15]$.

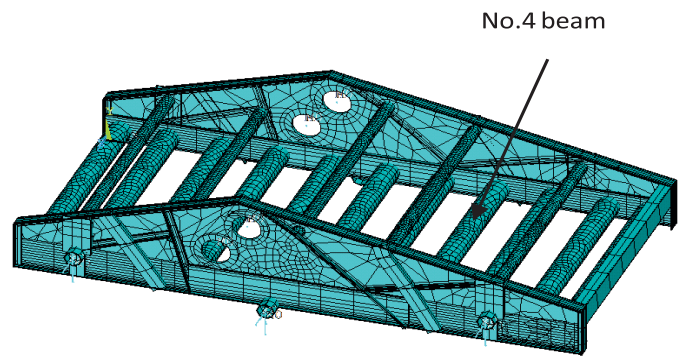

Fig. 1. Finite element model of the vibrating screen fatigue crack

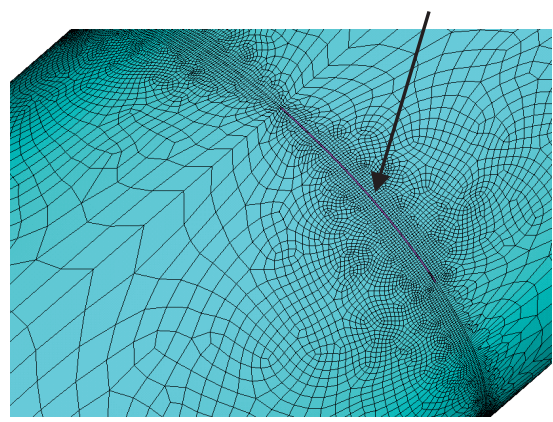

Fig. 2. The simulated fatigue crack of the No. 4 beam

The beam of the vibrating screen is tubular structure, so the fatigue crack is shell crack type. The critical crack length of the beam can be calculated by Eq. (9):

$a_{c}=\frac{1}{\pi}\left(\frac{K_{I C}}{f \sigma_{\max }}\right)^{2}$

where $K_{I C}$ is fracture toughness, $f$ is geometrical factor, $\sigma_{\max }$ is the maximum cyclic stress $[16,17]$. Since the material of the beam is 20 carbon steel, $K_{I C}=104 \mathrm{MPa} \cdot \mathrm{m}^{1 / 2}, f=1.5$, $\sigma_{\max }=60 \mathrm{MPa}$. the critical crack length $a_{c}$ is equal to $425 \mathrm{~mm}$. In order to analyze the relationship between strain modal change ratio and the fatigue residual life of the beam, the displacement and strain modal parameters were calculated according $10 \%$ to $90 \%$ of the critical crack size, respectively (i.e., beam fatigue damage degree).

The beam was meshed with SHELL181 element, which has 12950 nodes and 12884 elements. The Block Lanczos method was used to extract the modal parameters, the first five modal frequencies of the intact and damaged beam are shown in Table 1, the relative deviation is $\eta=\left(f_{p}-f_{c}\right) / f_{p}$. The modal frequencies of the damaged beam decrease compared to intact beam as shown in Table 1 . The reason is the fatigue crack caused the stiffness reduction for the damaged beam but the mass remains the same compared to intact beam, according to the Eq. (2), the modal frequency values must be reduced. The maximum relative deviation of the modal frequency is $4.06 \%$ before and after damage. As the modal frequencies have not obviously change before and after damage, using modal frequency as index of damage detection is not effective and hard to judge the damage location.

Table 1. The modal frequencies of the intact and damaged beam

\begin{tabular}{|c|c|c|c|c|c|}
\hline Mode & $\begin{array}{c}\text { Intact beam } \\
f_{p} / \mathrm{Hz}\end{array}$ & $\begin{array}{c}\text { Damaged 50 \% } \\
f_{c} / \mathrm{Hz}\end{array}$ & $\begin{array}{c}\text { Relative deviation } \\
\eta / \%\end{array}$ & $\begin{array}{c}\text { Damaged 90 \% } \\
f_{c} / \mathrm{Hz}\end{array}$ & $\begin{array}{c}\text { Relative deviation } \\
\eta / \%\end{array}$ \\
\hline 1 & 137.98 & 137.01 & 0.7 & 133.48 & 3.26 \\
\hline 2 & 344.02 & 343.49 & 0.15 & 331.11 & 3.75 \\
\hline 3 & 390.98 & 388.41 & 0.66 & 379.9 & 2.83 \\
\hline 4 & 495.64 & 494.03 & 0.32 & 486.16 & 1.91 \\
\hline 5 & 635.95 & 633.05 & 0.46 & 610.14 & 4.06 \\
\hline
\end{tabular}

The displacement and strain modal parameters of the finite element model were calculated, the first order of the displacement mode shape is shown in Fig. 3(a), the strain mode shape is shown in Fig. 3(b) when the beam damaged 60 percent. The maximum amplitude of the modal strain 
generates at the midpoint along the beam length direction because of the fatigue crack existence.

Since Fig. 3 is contour plot which is inconvenient to quantify the strain modal change rate, so we selected the generatrix along the beam length direction and analyzed strain modal change tendency along the beam length. When the beam fatigue damage degree is 30 percent, the first 3 mode shapes are shown in Fig. 4. Fig. 4(a) is the displacement mode shape, which is not visible mutation when the beam generate fatigue crack, Fig. 4(b) is the strain mode shapes, which has mutation peaks at the quarter and midpoint of the beam because of the fatigue crack. Fig. 4 shows that strain modal parameters are more sensitive to the crack damage than the displacement modal parameters. Thus, according to Eq. (8), we select the strain modal change ratio $(S R)$ as the damage index which is sensitive and effective.
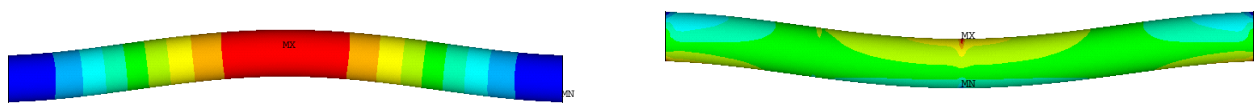

a) The first displacement mode shape

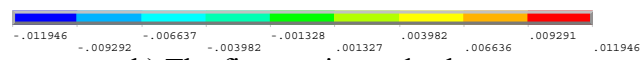

b) The first strain mode shape

Fig. 3. The first mode of the beam damaged 60 percent
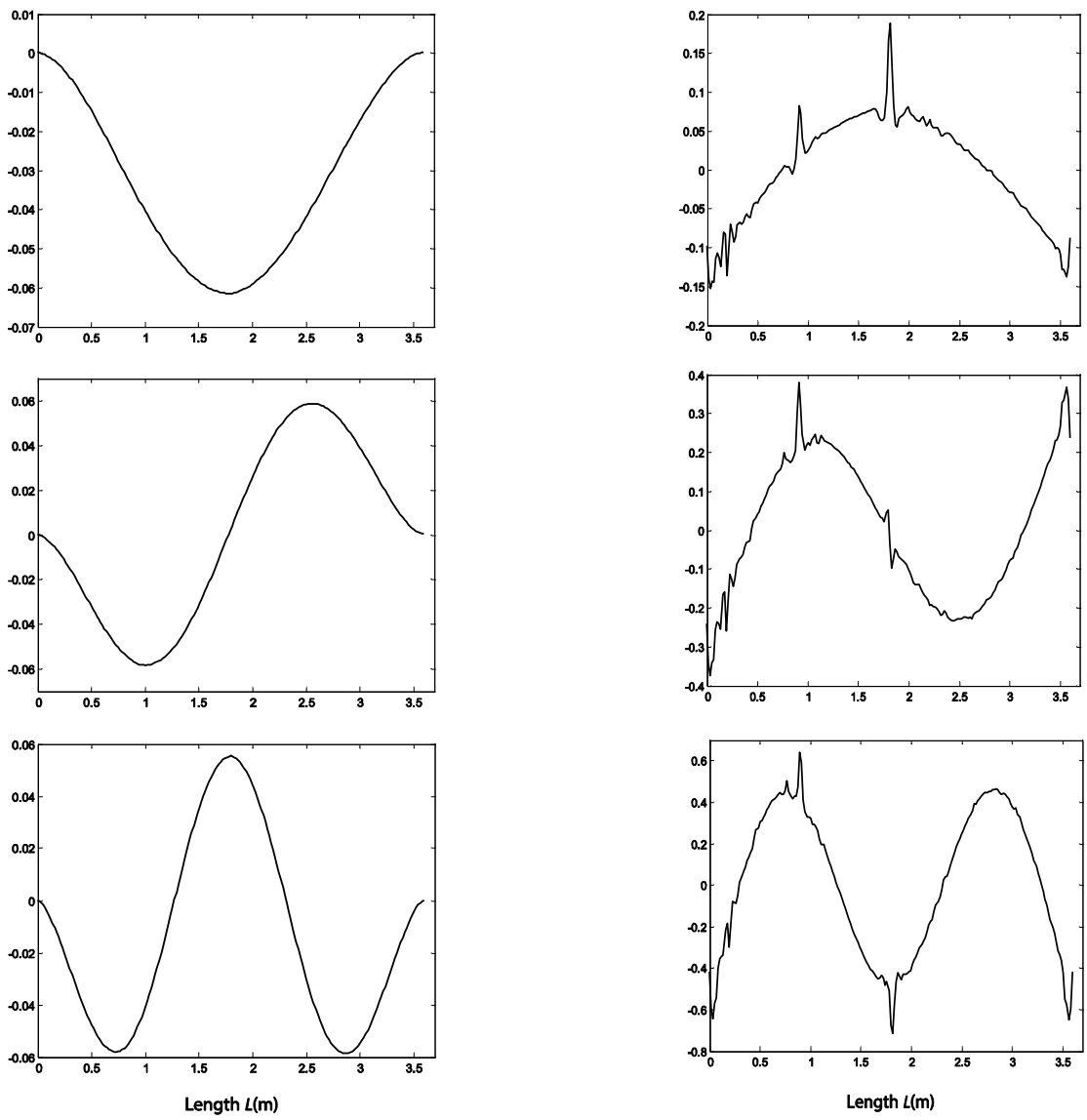

a) Displacement mode shapes

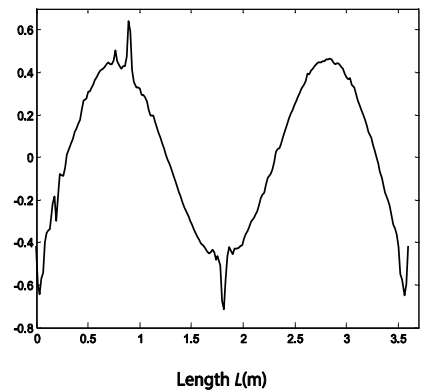

b) Strain mode shapes

Fig. 4. The first 3 displacement and strain mode shapes 
The comparison of the strain mode shapes with different damage degree is shown in Fig. 5, the strain mode shapes generate mutation peak at the damaged location. The amplitudes of the mutation peak increase with the damage degree increasing at the quarter and midpoint of the beam. The reason is with the damage degree increasing the fatigue crack length extend, which lead to the stiffness of the structure decrease at the damaged location.

The strain modal change ratios with different damage degree are shown in Fig. 6, including the first 3 strain modes and the least squares fitting values. With the damage degree increase, the strain modal change ratios increase with similar trend among the strain modes. When the damage degree is less than $60 \%$, the strain modal ratio increase with slow steady growth, but after the damage degree is more than $60 \%$, the strain modal ratio increase rapidly with the crack propagation. The relationship between the damage degree and the strain modal change ratio can be fitted by least square method as shown in Eq. (10):

$S R=4.85 \times 10^{-7} d^{4}-7.68 \times 10^{-5} d^{3}+4.21 \times 10^{-3} d^{2}-0.07 d+0.55, \quad 0<d<1$.

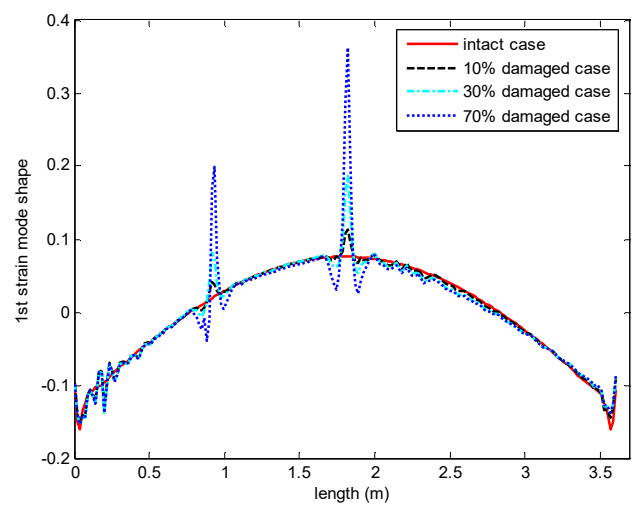

Fig. 5. The first order strain mode shapes versus different damage degree

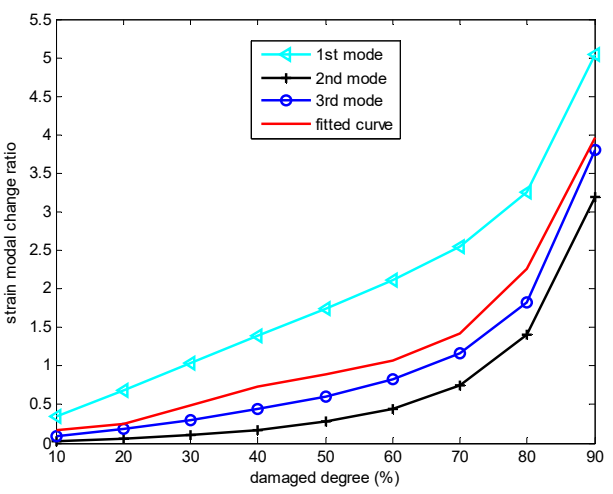

Fig. 6. The strain modal change ratio versus different damage degree

\section{The fatigue residual life of the vibrating screen beam}

The fatigue life of the vibrating screen beam includes crack initiation life and crack propagation life. When the stress intensity factor $K_{I}$ is greater than the fatigue crack propagation threshold $\Delta K_{t h}$, the crack growth is in a stable stage, the relationship between the crack propagation rate $d a / d N$ and $K_{I}$-factor range $\Delta K_{I}$ can be described by Paris law:

$\frac{d a}{d N}=C\left(\Delta K_{I}\right)^{m}$

where $a$ is crack length, $N$ is number of loading cycles, $C, m$ is material constant, $C=2.11 \times 10^{-11}, m=2.48$ :

$\Delta K_{I}=f \Delta \sigma \sqrt{\pi a}$

Substitute Eq. (12) into Eq. (11) and integral, fatigue crack propagation residual life $N_{f}$ can be deduced:

$N_{f}=\frac{a_{c}^{1-0.5 m}-a_{0}^{1-0.5 m}}{(1-0.5 m) C(f \Delta \sigma \sqrt{\pi})^{m}}, \quad m \neq 2$,

where $a_{c}$ is critical crack length, $a_{0}$ is initial crack length, $f$ is geometrical factor, $\Delta \sigma$ is stress 
amplitude [18].

The relationship between initial crack length and the logarithmic fatigue residual life is shown in Fig. 7, with the increase of initial crack length, the crack propagation residual life declined. When the initial crack length is less than $50 \%$ of the critical crack length, the crack propagation residual life declines rapidly.

Therefore, based on the strain modal analysis, the relationship between the strain modal change ratio and damage degree can be expressed by Eq. (10), the initial crack length is equivalent to the damage degree, then the fatigue crack propagation residual life can be calculated by Eq. (13).

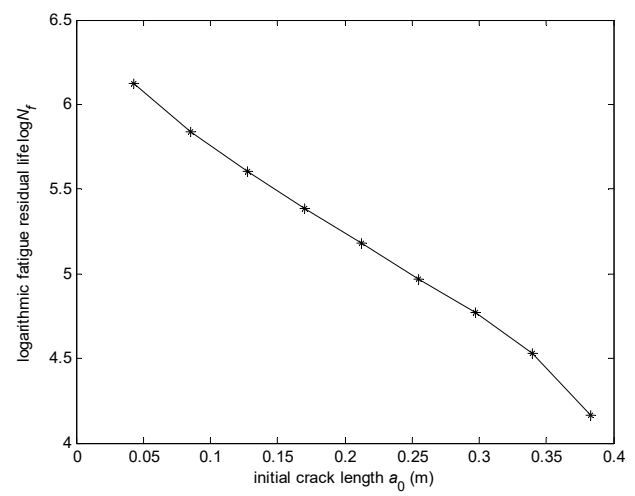

Fig. 7. The fatigue residual life versus different initial crack length

\section{Conclusions}

The displacement and strain modal analysis of the damaged beam were carried out, the results show that the modal frequencies deviation of the damaged beam is small compared to the intact beam, the displacement mode shapes have no obvious change likewise, but the strain mode shapes have mutation peaks at the damaged location. From the modal analysis results we found that taking the strain modal change ratio as the damage index has advantages of high sensitivity and good reliability. The strain modal change ratio can be calculated according to the damage degree of the beam, then the fatigue crack propagation residual life can be calculated by Paris law according to the initial crack length.

\section{Acknowledgements}

Financial support for this work provided by the National Natural Science Foundation of China (Grant No. 51074094) and Shandong Provincial Natural Science Foundation of China (Grant No. ZR2015EM035) are gratefully acknowledged.

\section{References}

[1] Cleary P. W., Sinnott M. D., Morrison R. D. Separation performance of double deck banana screens - Part 1: Flow and separation for different accelerations. Minerals Engineering, Vol. 22, 2009, p. 1218-1229.

[2] Yantek D. S., Camargo H. R. Structural vibration as a noise source on vibrating screens. ASME International Mechanical Engineering Congress and Exposition, 2009, p. 213-222.

[3] Zhao L. L., Liu C. S., Yan J. X. A virtual experiment showing single particle motion on a linearly vibrating screen-deck. Mining Science and Technology, Vol. 20, Issue 2, 2010, p. 276-280.

[4] Peng L. P., Liu C. S., Song B. C., et al. Improvement for design of beam structures in large vibrating screen considering bending and random vibration. Journal of Central South University, Vol. 22, Issue 9, 2015, p. 3380-3388. 
[5] Yam L. H., Leung T. P., Li D. B., et al. Theoretical and experimental study of modal strain analysis. Journal of Sound and Vibration, Vol. 191, Issue 2, 1996, p. 251-260.

[6] Adewuyi A. P., Wu Z. S. Modal macro-strain flexibility methods for damage localization in flexural structures using long-gage FBG sensors. Structural Control and Health Monitoring, Vol. 18, Issue 3, 2011, p. 341-360.

[7] He L. J., Lian J. J., Ma B. Intelligent damage identification method for large structures based on strain modal parameters. Journal of Vibration and Control, Vol. 20, Issue 12, 2013, p. 1783-1795.

[8] Cha Y. J., Buyukozturk O. Structural damage detection using modal strain energy and hybrid multiobjective optimization. Computer-Aided Civil and Infrastructure Engineering, Vol. 30, Issue 5, 2015, p. 347-358.

[9] Wang Y. Y., Zhang Z. R. Similar experimental study of test model and prototype of vibrating screen. Journal of Mechanical Engineering, Vol. 47, Issue 5, 2011, p. 101-105.

[10] Kranjc T., Slavič J., Boltežar M. A comparison of strain and classic experimental modal analysis. Journal of Vibration and Control, Vol. 22, 2016, p. 371-381.

[11] Li D. B., Zhang Y. R., Luo J. Using modal analysis method in analyzing dynamic strain/stress field. Journal of Vibration and Shock, Vol. 4, 1992, p. 15-22.

[12] Li Y. Y., Cheng L., Yam L. H., et al. Identification of damage locations for plate-like structures using damage sensitive indices: strain modal approach. Computers and Structures, Vol. 80, Issue 25, 2002, p. 1881-1894.

[13] Baragetti S. Innovative structural solution for heavy loaded vibrating screens. Minerals Engineering, Vol. 84, 2015, p. 15-26.

[14] Fan J. L., Guo X. L. Numerical simulation on elastic-plastic fatigue crack growth behavior. Journal of Mechanical Engineering, Vol. 51, Issue 10, 2015, p. 33-40.

[15] Niu J., Zong Z. H., Chu F. P. Damage identification method of girder bridges based on finite element model updating and modal strain energy. Science China Technological Sciences, Vol. 58, Issue 4, 2015, p. 701-711.

[16] Chen L., Cai L. X. Research on fatigue crack growth behavior of materials by considering the fatigue damage near the crack tip. Journal of Mechanical Engineering, Vol. 48, Issue 20, 2012, p. 51-56.

[17] Bai X., Xie L. Y. Steady random load method to predict fatigue crack growth life. Acta Aeronautica et Astronautica Sinica, Vol. 35, Issue 9, 2014, p. 2500-2505.

[18] Zerbst U., Vormwald M., Pippan R., et al. About the fatigue crack propagation threshold of metals as a design criterion - a review. Engineering Fracture Mechanics, Vol. 153, 2016, p. 190-243. 